\title{
HERDABILIDADES E CORRELAÇÕES DA PRODUÇÃO DO FEIJÃO E DOS SEUS COMPONENTES PRIMÁRIOS, NAS ÉPOCAS DE CULTIVO DA PRIMAVERA-VERÃO E DO VERÃO-OUTONO
}

\author{
HERITABILITIES AND CORRELATIONS OF COMMON BEAN YIELD AND ITS PRIMARY \\ COMPONENTS, IN THE SPRING-SUMMER AND SUMMER-FALL CULTIVATION SEASONS
}

\author{
Antônio Daniel Fernandes Coelho ${ }^{1}$ Antônio Américo Cardoso ${ }^{2}$ Cosme Damião Cruz $^{3}$ \\ Geraldo Antônio de Andrade Araújo ${ }^{2}$ Marcos Ribeiro Furtado ${ }^{3}$ \\ Cláudio Lúcio Fernandes Amaral ${ }^{4}$
}

RESUMO

Este trabalho teve como objetivo estimar parâmetros genéticos em populações $F_{2}$ do feijoeiro (Phaseolus vulgaris L.), cultivadas em duas épocas tradicionais no Estado de Minas Gerais. Foi realizado o cruzamento entre os cultivares 'Ouro 1919' e 'Milionário 1732', e as populações genitoras, $F_{1}$ e $F_{2}$ foram cultivadas na primavera-verão e no verão-outono. Nas duas épocas, as estimativas de herdabilidades foram baixas para todos os caracteres e o número de vagens por planta apresentou as maiores correlações fenotípicas e de ambiente com a produção de grãos.

Palavras-chave: Phaseolus vulgaris L., parâmetros genéticos.

SUMMARY

This work aimed to estimate genetic parameters in $F_{2}$ populations of the common bean (Phaseolus vulgaris L.), cultivated in two traditional seasons in Minas Gerais State (Brazil). The cultivars 'Ouro 1919' and 'Milinário 1732' were crossed, and the parental, $F_{1}$ and $F_{2}$ populations were cultivated in the spring-summer and summer-fall. In the two cultivation seasons, the heritabilities were low for all characters, while the number of pods per plant showed the greatest phenotypic and environmental correlations with grain yield.

Key words: Phaseolus vulgaris L., genetic parameters.

\section{INTRODUÇÃO}

As épocas tradicionais de cultivo do feijoeiro em Minas Gerais são a primavera-verão e o verão-outono (VIEIRA et al., 1991; CHAGAS, 1994; VIEIRA \& VIEIRA, 1995). O feijão da primavera-verão é semeado no período de setembro a dezembro e o do verão-outono, de fevereiro a março (VIEIRA et al., 1991).

Apesar destas épocas apresentarem condições ambientais bem distintas, não existem cultivares específicos para cada uma delas. COSTA et al. (1997) relataram que os cultivares de feijão utilizados em Minas Gerais foram, em geral, selecionados e testados apenas em condições de monocultivo, mas nem sempre em cada uma dessas épocas. A presença de interações genótipos $\mathrm{X}$ ambientes evidencia que o melhoramento do feijoeiro deve ser feito nas condições mais semelhantes às utilizadas normalmente pelos agricultores (SANTOS et $\boldsymbol{a l}$., 1985). No caso de ocorrência de interações genótipos $\mathrm{X}$ épocas de cultivo, os genótipos deverão ser selecionados durante os ensaios conduzidos nas épocas para as quais eles se destinam.

\footnotetext{
${ }^{1}$ Engenheiro Agrônomo, Doutor, Rua Manoel Rodrigues da Silva, 03, Bairro José Brandão, 34800-000, Caeté-MG. E-mail: daniel@cnpgl.embrapa.br. Autor para correspondência.

${ }^{2}$ Engenheiro Agrônomo, Doutor, Professor do Departamento de Fitotecnia da Universidade Federal de Viçosa (UFV).

${ }^{3}$ Engenheiro Agrônomo, Doutor, Professor do Departamento de Biologia Geral da UFV.

${ }^{4}$ Biólogo, Doutor, Professor do Departamento de Biologia da Universidade Federal de Juiz de Fora.
} Recebido para publicação em 09.02.01. Aprovado em 30.05.01 
O melhoramento do feijoeiro visando ao aumento da produtividade vem sendo feito de maneira quase empírica no Brasil, uma vez que as informações sobre o controle genético da produção de grãos e de seus componentes primários, para a diversidade de ambientes nos quais se explora a cultura, são deficientes. A determinação do controle genético dos caracteres constitui uma etapa inicial, que permite a escolha de procedimentos mais adequados (SANTOS et al., 1985). As estimativas de correlações fenotípicas e genotípicas entre caracteres são úteis no planejamento e na avaliação de programas de melhoramento. $\mathrm{O}$ conhecimento de correlações que existem entre importantes caracteres pode facilitar a interpretação dos resultados já obtidos e prover a base para o planejamento de programas mais eficientes no futuro (JOHNSON et al.,1955). Caso as correlações genotípicas entre caracteres importantes e aqueles de menor importância econômica sejam de alta magnitude, estes poderão ser úteis em trabalhos com seleção indireta que visam à melhoria dos primeiros.

Diante desses aspectos, foi conduzido o presente trabalho, com o objetivo de estimar as herdabilidades dos caracteres produção de grãos por planta, número de vagens por planta, número de grãos por vagem e peso médio de 100 grãos, bem como os coeficientes de correlação genotípica, fenotípica e de ambiente entre os mesmos, nas populações $F_{2}$, oriundas do cruzamento 'Ouro 1919' X 'Milionário 1732', cultivadas nas épocas da primavera-verão e do verão-outono.

\section{MATERIAL E MÉTODOS}

Os experimentos de feijão foram conduzidos na Universidade Federal de Viçosa, situada na Zona da Mata de Minas Gerais, a $20^{\circ}$ $45^{\prime} \mathrm{S}$ de latitude, $42^{\circ} 51^{\prime} \mathrm{W}$ de longitude e 673 metros de altitude. $\mathrm{O}$ experimento da primaveraverão foi instalado em novembro de 1995 e o do verão-outono, em fevereiro de 1996.

A região de Viçosa caracteriza-se pelo clima Cwa, segundo Köppen, com médias anuais de precipitação e de temperatura equivalentes a $1221,4 \mathrm{~mm}$ e $19,4^{\circ} \mathrm{C}$, respectivamente. $\mathrm{O}$ mês mais quente apresenta temperatura média de $22,3^{\circ} \mathrm{C}$ e o mais frio, $15,4^{\circ} \mathrm{C}$. A precipitação apresenta-se concentrada no período de novembro a março (BOARETT et al., 1998). O solo do campo experimental é um argisolo câmbico. As condições climáticas, ocorridas durante o período de condução dos experimentos, encontram-se resumidas na tabela 1 .
Tabela 1 - Resumo das condições climáticas ocorridas na Universidade Federal de Viçosa - MG, durante os períodos da primavera-verão (novembro/1995 a janeiro/1996) e do verão-outono (fevereiro a abril/1996).

\begin{tabular}{|c|c|c|c|c|c|}
\hline \multirow[b]{2}{*}{ Mês/ano } & \multicolumn{3}{|c|}{ Temperatura média $\left({ }^{\circ} \mathrm{C}\right)$} & \multirow{2}{*}{$\begin{array}{l}\text { Umidade relativa } \\
(\%)(\text { média })\end{array}$} & \multirow{2}{*}{$\begin{array}{c}\text { Precipitação } \\
\text { total }(\mathrm{mm})\end{array}$} \\
\hline & Máx & Mín. & Média & & \\
\hline embro/1995 & 26,00 & 16,92 & 20,78 & 78,11 & 253,9 \\
\hline zembro/1995 & 26,96 & 18,19 & 21,74 & 86,59 & 342,2 \\
\hline eiro/1996 & 29,20 & 18,43 & 23,00 & 79,06 & 85,2 \\
\hline vereiro/1996 & 30,57 & 18,56 & 23,48 & 77,01 & 72,5 \\
\hline \arço/1996 & 29,98 & 18,49 & 23,02 & 81,05 & 99,0 \\
\hline bril/1996 & 27,02 & 15,20 & 20,01 & 80,31 & 94,8 \\
\hline
\end{tabular}

As populações $\mathrm{F}_{2}$ foram obtidas do cruzamento 'Ouro 1919' X 'Milionário 1732'. Estes genitores foram escolhidos por serem produtivos, por possuírem hábito de crescimento tipo II, o que confere resistência ao acamamento, e pela boa adaptação às condições de cultivo da Zona da Mata. O cultivar 'Ouro 1919' apresenta flores brancas e grãos de cor creme, enquanto o 'Milionário 1732' tem flores violetas e grãos pretos. Como a cor de flor violeta é dominante em relação à cor branca, 'Ouro 1919' foi utilizado como genitor feminino, de maneira a permitir a distinção fenotípica entre as plantas $\mathrm{F}_{1}$ e aquelas originárias de autofecundação. Os cruzamentos foram realizados em casa de vegetação.

As populações $F_{2}$ foram conduzidas separadamente nas épocas de cultivo da primaveraverão e do verão-outono. Além das sementes $F_{2}$, foram semeados os genitores e $F_{1}$, para que os efeitos ambientais pudessem ser estimados. A semeadura foi realizada em sulcos, espaçados de $0,50 \mathrm{~m}$, com dez sementes por metro linear. Foi empregado o delineamento inteiramente casualizado, com quatro repetições. No caso dos genitores e da $F_{1}$, foram utilizadas 13 sementes por parcela, ficando esta com área de $0,65 \mathrm{~m}^{2}$. Já para a população $\mathrm{F}_{2}$, foram empregadas 125 sementes por parcela $\left(6,25 \mathrm{~m}^{2}\right)$. Um maior tamanho de parcela, utilizado para avaliar a $\mathrm{F}_{2}$, foi devido ao fato de essa população, ao contrário das populações dos genitores e da $F_{1}$, apresentar variabilidade genética; assim, um maior número de plantas por parcela permitiria uma melhor amostragem da diversidade de genótipos presentes na $\mathrm{F}_{2}$. A adubação empregada foi o equivalente a $350 \mathrm{~kg}$ de 4-14-8 e a 90kg de uréia por hectare, empregados, respectivamente, no dia da semeadura e cerca de 40 dias após.

De cada planta, foram avaliados os seguintes caracteres: produção de grãos (em gramas) (PROD), número de vagens por planta (NVP), número de grãos por vagem $(\mathrm{NGV})$ e peso médio de 100 grãos (P100G). 
As herdabilidades, no sentido amplo, para os caracteres PROD, NVP, NVG e P100G foram estimadas a partir da seguinte expressão, citada por CRUZ \& REGAZZI (1997):

$$
\begin{aligned}
& \mathrm{h}^{2}=\frac{\hat{\sigma}_{\mathrm{g}(\mathrm{F} 2)}^{2}}{\hat{\sigma}_{\mathrm{f}(\mathrm{F} 2)}^{2}} \text {, em que } \\
& \hat{\sigma}_{g(\mathrm{~F} 2)}^{2}=\hat{\sigma}_{\mathrm{f}(\mathrm{F} 2)}^{2}-\hat{\sigma}_{\mathrm{m}(\mathrm{F} 2)}^{2} ; \\
& \hat{\sigma}_{\mathrm{m}(\mathrm{F} 2)}^{2}=1 / 4\left[\hat{\sigma}_{\mathrm{f}(\mathrm{P} 1)}^{2}+\hat{\sigma}_{\mathrm{f}(\mathrm{P} 2)}^{2}+2 \hat{\sigma}_{\mathrm{f}(\mathrm{F} 1)] ;}^{2}\right. \\
& \hat{\sigma}_{g(\mathrm{~F} 2)}^{2} \text { e } \hat{\sigma}_{\mathrm{f}(\mathrm{F} 2)}^{2}=\text { estimativas das variâncias } \\
& \text { genotípica e fenotípica entre as plantas } \mathrm{F}_{2} \text {, } \\
& \text { respectivamente; } \\
& \hat{\sigma}_{\mathrm{m}(\mathrm{F} 2)}^{2}=\text { estimativa da variância atribuída ao meio; } \\
& \hat{\sigma}_{\mathrm{f}(\mathrm{P} 1)}^{2} \text { e } \hat{\sigma}_{\mathrm{f}(\mathrm{P} 2)}^{2}=\text { estimativas das variâncias }
\end{aligned}
$$
fenotípicas entre as plantas dos genitores 1 e 2 , respectivamente; e

$\hat{\sigma}_{\mathrm{f}(\mathrm{F} 1)}^{2}=$ estimativa da variância fenotípica entre as plantas $\mathrm{F}_{1}$.

Os coeficientes de correlação genotípica, fenotípica e de ambiente entre os caracteres PROD, NVP, NGV e P100G foram estimados a partir da seguinte expressão:

$$
r_{x y}=\frac{\operatorname{côv}(x, y)}{\sqrt{\hat{v}(x) \cdot \hat{v}(y)}}, \text { em que }
$$

$\operatorname{côv}(\mathrm{x}, \mathrm{y})=$ estimativa da covariância entre os caracteres $\mathrm{x}$ e $\mathrm{y}$;

$\hat{\mathrm{v}}(\mathrm{x}) \quad \hat{\mathrm{v}}(\mathrm{y})=$ estimativa da variância dos caracteres $\mathrm{x}$ e $\mathrm{y}$, respectivamente.

A expressão para estimação das covariâncias genotípicas, utilizadas para o cálculo dos coeficientes de correlação genotípica, foi desenvolvida em analogia à expressão apresentada por CRUZ \& REGAZZI (1997) para cálculo da variância genotípica:

$\operatorname{côv}_{\mathrm{g}}(\mathrm{x}, \mathrm{y})=\operatorname{côv} \mathrm{f}_{\mathrm{f}}(\mathrm{x}, \mathrm{y})-\operatorname{côv}_{\mathrm{m}}(\mathrm{x}, \mathrm{y})$, em que $\operatorname{côv}_{\mathrm{m}}(\mathrm{x}, \mathrm{y})=1 / 4\left[\operatorname{côv}_{\mathrm{fP} 1}(\mathrm{x}, \mathrm{y}),+\operatorname{côv}_{\mathrm{f} \mathrm{P} 2}(\mathrm{x}, \mathrm{y})+\right.$ $2 \operatorname{côv}_{\mathrm{fF} 1}(\mathrm{x}, \mathrm{y})$ ]

côv $\mathrm{g}_{\mathrm{g}}(\mathrm{x}, \mathrm{y}), \operatorname{cô}_{\mathrm{f}}(\mathrm{x}, \mathrm{y})$ e $\operatorname{côv}_{\mathrm{m}}(\mathrm{x}, \mathrm{y})=$ covariâncias genotípica, fenotípica e de ambiente entre os caracteres $\mathrm{x}$ e $\mathrm{y}$, observadas entre as plantas $\mathrm{F}_{2}$, respectivamente; côv ${ }_{\mathrm{f}}{ }_{\mathrm{P} 1}(\mathrm{x}, \mathrm{y})$ e côv $\mathrm{f}_{\mathrm{P} 2}(\mathrm{x}, \mathrm{y})=$ covariâncias fenotípicas entre os caracteres $\mathrm{x}$ e $\mathrm{y}$, observadas entre as plantas dos genitores 1 e 2 , respectivamente; e côv ${ }_{\mathrm{f} F 1}(\mathrm{x}, \mathrm{y})=$ covariância fenotípica entre os caracteres $\mathrm{x}$ e $\mathrm{y}$, observada entre as plantas $\mathrm{F}_{1}$.

\section{RESULTADOS E DISCUSSÃO}

A produtividade de todos os genótipos avaliados foi muito superior no verão-outono (Tabela 2). Na primavera-verão, a intensa competição com plantas daninhas e a ocorrência de encharcamento do solo, que provoca a morte do feijoeiro, foram os responsáveis pelo baixo rendimento. Em ambas as estações, verifica-se uma maior produtividade da $F_{1}$, conseqüência do vigor híbrido.

As estimativas das herdabilidades, no sentido amplo, de todos os caracteres foram baixas nas duas épocas de cultivo (Tabela 3). Este resultado pode ser explicado pelo fato de a produção de grãos e os seus componentes primários serem poligênicos e, portanto, muito influenciados pelo ambiente (RAMALHO et al., 1993).

$\mathrm{Na}$ primavera-verão, a estimativa de herdabilidade da produção de grãos obtida foi negativa. Isso é possível em razão do estimador utilizado, em que a variância genotípica é obtida subtraindo a estimativa da variância ambiental da estimativa da variância fenotípica. Essa estimativa negativa indica que a variância genotípica desse caráter é nula ou de pequena magnitude (SEARLE $\boldsymbol{e t}$ al., 1992).

A maior estimativa de herdabilidade foi verificada para o número de vagens por planta, na época da primavera-verão $(0,34)$. Estimativas de maior magnitude de herdabilidade para o número de vagens por planta têm sido verificadas por vários autores, dentre os quais podem ser citados SANTOS (1981), PETERNELLI et al. (1994) e LANA (1996).

Estimativas de herdabilidades maiores que zero, para todos os caracteres, só foram observadas no verão-outono. Tal fato, certamente, foi devido às condições ambientais mais favoráveis nesta época, isto é, baixa infestação por plantas daninhas e ausência de encharcamento do solo, o que diminuiu a variância devido ao meio e permitiu a obtenção de estimativas positivas para a variância genotípica. Nesta época, a menor estimativa foi para a produção de grãos $(0,19)$, enquanto o número de grãos por vagens e o peso médio de 100 grãos apresentaram os maiores valores $(0,33)$. Resultados semelhantes foram observados por RAMALHO $\boldsymbol{e t}$ al. (1979), na época da primavera-verão. Eles 
Tabela 2 - Produtividade de grãos (Kg/hectare) dos genótipos avaliados nos períodos da primavera-verão (novembro/1995 a janeiro/1996) (PV) e do verão-outono (fevereiro a abril/1996) (VO), na Universidade Federal de Viçosa - MG.

\begin{tabular}{lcccc}
\hline & \multicolumn{4}{c}{ Genótipo } \\
\cline { 2 - 5 } Período & 'Ouro 1919' (P1) & 'Milionário 1732' (P2) & $\mathrm{F}_{1}(\mathrm{P} 1 \times \mathrm{x} 2)$ & $\mathrm{F}_{2}(\mathrm{P} 1 \times \mathrm{P} 2)$ \\
\hline PV & 231 & 225 & 432 & 246 \\
VO & 2511 & 2661 & 3385 & 2608 \\
\hline
\end{tabular}

Vários autores, dentre eles PINCHINAT \& ADAMS (1966), COYNE (1968), DUARTE \& ADAMS (1972), CASTOLDI (1991), PETERNELLI et al. (1994) e LANA (1996), verificaram que o número de vagens por planta é o caráter que mais contribui para o rendimento de grãos do feijoeiro, uma vez que apresenta as maiores correlações com a produção de grãos. Trabalhando com análise de trilha, COIMBRA et al. (1999b)

verificaram estimativas de herdabilidades dos componentes primários da produção superiores à da produção de grãos.

As estimativas dos coeficientes de correlação fenotípica, genotípica e de ambiente, entre os quatro caracteres avaliados nas épocas da primavera-verão e do verão-outono, encontram-se na tabela 4.

Em virtude de a estimativa de variância genotípica na primavera-verão ter sido negativa, as correlações genotípicas só puderam ser calculadas para o verão-outono. Nesta estação, o número de vagens por planta apresentou alta correlação com a produção de grãos. Assim, a seleção de plantas com maior número de vagens irá proporcionar maiores ganhos para a produção do que a seleção de plantas mais produtivas, uma vez que o número de vagens apresentou maior estimativa de herdabilidade (CRUZ \& REGAZZI, 1997). Já o peso médio dos grãos apresentou correlação negativa com a produção, sendo que a seleção de plantas com grãos maiores irá ocasionar diminuição na produtividade.

As correlações fenotípica e ambiental entre a produção de grãos e os seus componentes primários (número de vagens por planta, número de grãos por vagem e peso médio de 100 grãos) foram positivas nas duas épocas. Dentre este três componentes, o que apresentou as maiores estimativas de correlação com a produção de grãos, nas duas épocas, foi o número de vagens por planta.

Tabela 3 - Estimativas das herdabilidades, no sentido amplo, dos caracteres produção de grãos/planta (PROD), número de vagens/planta (NVP), número de grãos/vagem (NGV) e peso médio de 100 grãos (P100G), obtidas na geração $\mathrm{F}_{2}$ do cruzamento 'Ouro 1919 ' x 'Milionário 1732'. Universidade Federal de Viçosa - MG, 1995/1996.

\begin{tabular}{lcccc}
\hline Época de Cultivo & PROD & NVP & NGV & P100G \\
\hline Primavera-Verão & $-0,01$ & 0,34 & 0,17 & 0,19 \\
Verão-Outono & 0,19 & 0,25 & 0,33 & 0,33 \\
\hline
\end{tabular}

verificaram que o número de vagens por planta e o peso médio de 100 grãos apresentaram o maior efeito direto sobre a produção de grãos dessa leguminosa.

No geral, nas duas épocas, os coeficientes de correlação entre os componentes primários da produção foram muito baixos ou negativos. Resultados semelhantes têm sido relatados por vários pesquisadores, dentre eles PINCHINAT \& ADAMS (1966), ADAMS (1967), DUARTE \& ADAMS (1972), AGGARWALL \& SINGH (1973), GONÇALVES (1979), PEREIRA (1984), NIENHUIS \& SINGH (1986), CASTOLDI (1991), PETERNELLI et al. (1994), LANA (1996) e COIMBRA et al. (1999a).

Correlações negativas entre os componentes primários da produção de grãos ocorrem na maioria das culturas, principalmente em condições de estresse ambiental, que podem não permitir a máxima expressão dos genes que controlam estes componentes. Acredita-se que tais correlações sejam devido à ação do ambiente sobre componentes geneticamente independentes, que se desenvolvem de uma maneira seqüencial, ou seja, primeiro tem-se o número de vagens por planta, depois o número de grãos por vagem e, por último, o peso destes grãos (ADAMS,1967). Quando fatores ambientais limitantes causam intensa competição entre as plantas, há também intensa competição entre diferentes partes da planta por nutrientes e metabólitos. Esta competição é particularmente expressiva durante a formação das estruturas reprodutivas, o que resulta em uma variação compensatória entre os componentes primários da produção (LANA, 1996).

A maioria dos coeficientes de correlação ambiental foi positiva, o que indica que os pares de caracteres avaliados são beneficiados ou prejudicados pelas mesmas causas de variações ambientais (CRUZ \& REGAZZI, 1997). Coeficientes de correlação ambiental positivos também foram relatados por LANA (1996). 
Tabela 4 - Estimativas dos coeficientes de correlação genotípica (rg), fenotípica (rf) e ambiental (ra) entre os caracteres produção de grãos/planta (PROD), número de vagens/planta (NVP), número de grãos/vagem (NGV) e peso médio de 100 grãos (P100G), obtidas na geração $\mathrm{F}_{2}$ do cruzamento 'Ouro 1919' x 'Milionário 1732 ', cultivada na primavera-verão (PV) e no verão-outono (VO). Universidade Federal de Viçosa - MG, 1995/1996.

\begin{tabular}{|c|c|c|c|c|c|c|c|}
\hline \multicolumn{2}{|c|}{ Par de caracteres } & \multicolumn{2}{|c|}{ rg } & \multicolumn{2}{|c|}{$\mathrm{rf}$} & \multicolumn{2}{|c|}{ ra } \\
\hline & & PV & VO & PV & VO & PV & VO \\
\hline \multirow{3}{*}{ PROD } & NVP & $*$ & $>1,00$ & 0,71 & 0,96 & 0,80 & 0,94 \\
\hline & NGV & $*$ & 0,18 & 0,40 & 0,32 & 0,43 & 0,37 \\
\hline & P100G & $*$ & $-0,32$ & 0,29 & 0,08 & 0,27 & 0,17 \\
\hline \multirow[t]{2}{*}{ NVP } & NGV & $-0,81$ & 0,27 & $-0,16$ & 0,18 & $-0,05$ & 0,13 \\
\hline & P100G & 0,16 & $-0,13$ & 0,04 & $-0,06$ & $-0,05$ & $-0,02$ \\
\hline NGV & P100G & $<-1,00$ & $-0,58$ & 0,07 & $-0,25$ & 0,37 & $-0,10$ \\
\hline
\end{tabular}

* Não foi calculada a estimativa da correlação, em virtude de a estimativa da variância genotípica ter sido menor do que zero.

\section{CONCLUSÕES}

Nas duas estações, as estimativas de herdabilidade de todos os caracteres avaliados foram baixas, sendo que a maior estimativa foi para o número de vagens por planta, na primavera-verão.

Os coeficientes de correlação fenotípica e ambiental entre a produção de grãos por planta e os seus componentes primários foram todos positivos. Entre esses componentes, o número de vagens por planta foi o que apresentou as maiores correlações com a produção, em ambas estações. As correlações entre os componentes primários foram muito baixas ou negativas.

No verão-outono, maiores ganhos para a produção de grãos serão obtidos com a seleção de plantas que apresentem maiores números de vagens.

\section{REFERÊNCIAS BIBLIOGRÁFICAS}

ADAMS, M.W. Basis of yield component compensation in crop plants with special reference to the field bean, Phaseolus vulgaris. Crop Science, Madison, v.7, n.5, p.505-510,1967.

AGGARWALL, V.D., SINGH, S.P. Genetic variability and interrelation in agronomic traits in kidney-bean (Phaseolus vulgaris L.). Indian Journal of Agricultural Science, New Delhi, v.43, n.9, p.845-848, 1973.

BOARETT, W.A., SOUZA, C.M., WRUCK, F.J. Índice de erosividade das chuvas para Viçosa/MG. Revista Ceres, Viçosa, v.45, n.258, p.193-201, 1998.

CASTOLDI, F.L. Análise das interrelações entre rendimento e diversas características agronômicas do feijoeiro (Phaseolus vulgaris L). Viçosa - MG, 1991. 73p. Dissertação (Mestrado em Genética e Melhoramento) - Curso de Pós-graduação em Genética e Melhoramento, Universidade Federal de Viçosa, 1991.

CHAGAS, J.M. Considerações sobre a cultura do feijão no inverno em Minas Gerais. Informe Agropecuário, Belo Horizonte, v.17, n.178, p.5-8, 1994.

COIMBRA, J.L.M., GUIDOLIN, A.F., CARVALHO, F.I.F.de. Parâmetros genéticos do rendimento de grãos e seus componentes com implicações na seleção indireta em genótipos de feijão preto. Ciência Rural, Santa Maria, v.29, n.1, p.1-6, 1999a.

COIMBRA, J.L.M., GUIDOLIN, A.F., CARVALHO, F.I.F.de, et al. Análise de trilha I: análise do rendimento de grãos e seus componentes. Ciência Rural, Santa Maria, v.29, n.2, p.213-218, 1999 b.

COSTA, A.S.V. da, VIEIRA, C., CRUZ, C.D., et al. Comportamento de cultivares de feijão (Phaseolus vulgaris L.) em dez ambientes compreendendo cinco sistemas de produção. Revista Ceres, Viçosa, v.44, n.256, p.676-700,1997.

COYNE, D.P. Correlation, heritability and selection of yield components in field beans, Phaseolus vulgaris L. Proceedings of the American Society for Horticultural Science, Greensboro, v.93, p.388-396, 1968.

CRUZ, C.D., REGAZZI, A.J. Modelos biométricos aplicados ao melhoramento genético. 2. ed. Viçosa: UFV, 1997. 390p.

DUARTE, R.A., ADAMS, M.W. A path coefficient analysis of some yield component interrelation in field beans (Phaseolus vulgaris L). Crop Science, Madison, v.12. n.5, p.579-582, 1972.

GONÇALVES, M.C. Correlaç̃es genotípicas, fenotípicas e de ambiente em feijoeiro (Phaseolus vulgaris L). Viçosa MG, 1979. 42p. Dissertação (Mestrado em Genética e Melhoramento) - Curso de Pós-graduação em Genética e Melhoramento, Universidade Federal de Viçosa,1979.

JOHNSON, H.W ROBINSON, H.F, COMSTOCK, R.E Genotypic and phenotypic correlations in soybeans and their implications in selection. Agronomy Journal, Madison, v.47, n.10, p.477-483, 1955

LANA, A.M.Q. Avaliação de linhagens de feijão obtidas pelo método de melhoramento single seed descent (ssd) nos sistemas de plantio em monocultivo e consórcio com o milho. Viçosa - MG. 1996. 125p. Tese (Doutorado em Genética e Melhoramento) - Curso de Pós-graduação em Genética e Melhoramento, Universidade Federal de Viçosa, 1996.

NIENHUIS, J., SINGH, S.P. Combining ability analysis and relationship among yield, yield components and architectural traits in dry bean. Crop Science, Madison, v.26, n.1, p.2127,1986 .

PEREIRA, T.N.S. Estimativas de parâmetros genéticos na identificação de genitores para o melhoramento do feijoeiro-comum. Viçosa - MG, 1984. 55p. Dissertação (Mestrado em Genética e Melhoramento) - Curso de Pósgraduação em Genética e Melhoramento, Universidade Federal de Viçosa, 1984.

PETERNELLI, L.A., CARDOSO, A.A., CRUZ, C.D., et al Herdabilidades e correlações do rendimento do feijão e seus componentes primários no monocultivo e no consórcio. Revista Ceres, Viçosa, v.41, n.235, p.306-316, 1994.

PINCHINAT, A.M., ADAMS, M.W. Yield components in beans, as affected by intercrossing and neutron irradiation. Turrialba, Coronado, v.16, n.3, 247-252, 1966.

RAMALHO, M.A.P., ANDRADE, L.A.B., TEIXEIRA, N.C.S. Correlações genéticas e fenotípicas entre caracteres do feijão (Phaseolus vulgaris L.). Ciência e Prática, Lavras, v.3, n.1, p.63-70,1979. 
RAMALHO, M.A.P., SANTOS, J.B. dos, ZIMMERMANN, M.J. de O. Genética quantitativa em plantas alógamas: aplicações ao melhoramento do feijoeiro. Goiânia : UFG, 1993. $271 \mathrm{p}$

SANTOS, J.B. dos, VENCOVSKY, R., RAMALHO, M.A.P Controle genético da produção de grãos e de seus componentes primários em feijoeiro. Pesquisa Agropecuária Brasileira Brasília, v.20, n.10, p.1203-1211, 1985.

SANTOS, P.C. dos. Herdabilidades e correlações do rendimento com seus componentes, em dois cruzamentos de feijão-comum (Phaseolus vulgaris l.). Viçosa - MG, 1981. 60p. Dissertação (Mestrado em Genética e
Melhoramento) - Curso de Pós-graduação em Genética e Melhoramento, Universidade Federal de Viçosa, 1981

SEARLE, S.R., CASEllA, G., McCUllOCH, C.E. Variance components. New York : John Wiley \& Sons, 1992. 501p.

VIEIRA, C., ARAÚJO, G.A.de A., CHAGAS, J.M. Efeitos das datas de plantio sobre o feijão cultivado no outono-inverno. Pesquisa Agropecuária Brasileira, Brasília, v.26, n.6, p.863-873, 1991.

VIEIRA, C., VIEIRA, R.F. Épocas de plantio do feijão e propostas de nomenclatura para designá-las. Revista Ceres, Viçosa, v.42, n.244, p.685-688, 1995. 